\title{
Letter \\ Withholding and withdrawing life-sustaining treatment: the necessity of discrepancies in ethical reasoning
}

\author{
Frédéric Pochard ${ }^{1}$, Nancy Kentish-Barnes ${ }^{2}$ and Elie Azoulay ${ }^{1}$
}

1Famirea Group, Service de Réanimation Médicale, AP-PH, Saint Louis Hospital, 1 avenue Claude Vellefaux, University Paris 7, 75010 Paris, France
2Famirea Group and LAPSAC, AP-HP, Saint Louis Hospital, 1 avenue Claude Vellefaux, University Paris 7, 75010 Paris, France

Corresponding author: Elie Azoulay, elie.azoulay@sls.aphp.fr

Published: 29 April 2008

Critical Care 2008, 12:418 (doi:10.1186/cc6873)

This article is online at http://ccforum.com/content/12/2/418

(C) 2008 BioMed Central Ltd

See related research by Rydvall and Lynöe, http://ccforum.com/content/12/1/R13

Observations can be proposed regarding the study by Rydvall and Lynöe [1]. The use of standardised questionnaires in the general population measures the intention of the persons interviewed but not the reality of reasoning in a concrete clinical situation.

Most studies report that factors such as proxy comprehension and symptoms of anxiety or depression are major determinants of medical end-of-life decisions [2]. A study of the general population's wishes requires the use of random sampling; but before asking the population how they would react in theoretical situations, it seems important to first evaluate their knowledge. In a survey including 8,000 residents in France [3], only 28\% chose the correct definition of the intensive care unit. The population's answer reflects social need regarding an efficacious medical system of which the aim is to protect and save human life.

The objective of a consensus between physicians and the general population should not be considered an ethical shield: the consensus in itself has no ethical value. As discussion permits best decision-making, the existence of discrepancies between physicians and the general population is reassuring. There is no one good or bad decision or answer because, in practice, two different but valid decisions may be taken for the same case. Determinants of a decision to forgo life-sustaining treatments are not objective, are always context related, and remain independently associated with death after adjusting for comorbidities and severity at intensive care unit admission [4]. The results of studies focusing on end-of-life intentions depend on factors such as social coverage, medical culture (including intensive care unit admission policy), evolution of medical theories, practices and techniques, clinicians' experience and values, and the psychological and relational context of patient and proxies.

\section{Competing interests}

The authors declare that they have no competing interests.

\section{References}

1. Rydvall $A$, Lynöe N: Withholding and withdrawing life-sustaining treatment: a comparative study of the ethical reasoning of physicians and the general public. Crit Care 2008, 12:R13.

2. Azoulay E, Pochard F, Chevret S, Adrie C, Annane D, Bleichner G, Bornstain C, Bouffard Y, Cohen Y, Feissel M, GoldgranToledano D, Guitton C, Hayon J, Iglesias E, Joly LM, Jourdain M, Laplace C, Lebert C, Pingat J, Poisson C, Renault A, Sanchez O, Selcer D, Timsit JF, Le Gall JR, Schlemmer B; FAMIREA Study Group: Half the family members of intensive care unit patients do not want to share in the decision-making process: a study in 78 French intensive care units. Crit Care Med 2004, 32: 1832-1838.

3. Azoulay E, Pochard F, Chevret S, Adrie C, Bollaert PE, Brun F, Dreyfuss D, Garrouste-Orgeas M, Goldgran-Toledano D, Jourdain M, Wolff M, Le Gall JR, Schlemmer B: Opinions about surrogate designation outside the crisis setting: a population survey in France. Crit Care Med 2003, 31:1711-1714.

4. Azoulay E, Pochard F, Garrouste-Orgeas M, Moreau D, Montesino L, Adrie C, de Lassence A, Cohen Y, Timsit JF; Outcomerea Study Group: Decisions to forgo life-sustaining therapy in ICU patients independently predict hospital death. Intensive Care Med 2003, 29:1895-1901. 